\title{
Outcomes in superior transeptal and left atrial approach: does the number of valves matter?
}

\author{
Amer Harky ${ }^{1}$, Runzhi Chen ${ }^{2}$, and Andrew Muir ${ }^{1}$ \\ ${ }^{1}$ Liverpool Heart and Chest Hospital NHS Foundation Trust \\ ${ }^{2}$ University of Liverpool
}

May 26, 2020

Outcomes in superior transeptal and left atrial approach: does the number of valves matter?

Running Head: Approaches to the Mitral valve

Amer Harky MSc ${ }^{1,2}$, Runzhi Chen $\mathrm{MBBS}^{3}$, Andrew D Muir MD

1. University of Liverpool, Liverpool, UK

2. Department of Cardiothoracic Surgery, Liverpool Heart and Chest, UK

3. Faculty of Medicine, Imperial College London, UK

\section{Corresponding author}

Amer Harky

MRCS, MSc

Cardiothoracic Surgery

Liverpool Heart and Chest

UK

E-mail: aaharky@gmail.com

Tel: +44-151-600-1616

Funding: None

Conflict of interest: None

Key words : mitral valve, left atriotomy, transeptal

Dear Editor,

We read with interest the recent article by Izzat et al. [1] in which they concluded that superior transeptal approach (STS) for mitral valve surgery has equivocal clinical outcomes to left atriotomy (LA) aside from higher arrhythmia rates.

Whilst we agree with some of their conclusions, there are many aspects of this study that we question. In our recent meta-analysis, we compared 16 studies, a total of 4,537 patients, ( $\mathrm{n}=1,472$ for STS and $\mathrm{n}=3,065$ for LA) including two randomised trials [2]. STS was associated with higher rates of post-operative cardiac arrhythmias in cohorts that had combined or multiple cardiac procedures [2]. However, when comparing isolated mitral valve surgery through either LA or STS approach, all such differences were eliminated with no differences in cardiopulmonary bypass and aortic cross clamp times observed (98 \pm 27 vs $101 \pm 26$ minutes 
in LA and STS, WMD -3.20 minutes, 95\% CI [-16.02, 9.63], $p=0.62$ and $73 \pm 21$ vs $77 \pm 21$ minutes in LA and STS, WMD -2.51 minutes, $95 \%$ CI [-14.14, 9.12], $p=0.67$ respectively). Similarly, no differences in new post-operative atrial fibrillation or permanent pacemaker requirement were observed (RR 0.87, 95\% CI [0.68, $1.11], p=0.25$ and $\mathrm{RR} 0.72,95 \%$ CI $[0.41,1.26], p=0.25$ respectively).

It would therefore have been more robust for the authors to conduct a sub-analysis comparing isolated mitral valve surgery outcomes. We acknowledge that this would have been difficult as their STS cohort was associated with $94.2 \%$ additional interventions leaving either a very small comparison group or the potential for significant bias not limited to operative times and arrhythmia. Attempts at having more similar groups could have been attempted to avoid invalidating their conclusions [3]. Furthermore, the LA cases were done at a rate of 11 per year in the $1^{\text {st }}$ half of the study with the STS cases at 21 per year in the $2^{\text {nd }}$ half of the study. These differences would appear to be seniority related, meaning comparisons may be unwise.

\section{References:}

1. Izzat MB, Aljasem H, Alsharabi M, Hafez A. Comparison of safety and outcomes with two approaches to the mitral valve. J Card Surg. 2020;1-6. DOI:https://doi.org/10.1111/jocs.146036.

2. Harky A, Kusu-Orkar Ter-Er, Chan JSK, Noshirwani A, Savarimuthu S, Pousios D, Muir AD. Left atrial or transeptal approach for mitral valve surgery: a systematic review and meta-analysis, Current Problems in Cardiology (2020). DOI:https://doi.org/10.1016/j.cpcardiol.2020.100602

3. Al-Ghamdi B, Mallawi Y, Shafquat A, et al. Predictors of Permanent Pacemaker Implantation After Coronary Artery Bypass Grafting and Valve Surgery in Adult Patients in Current Surgical Era. Cardiol Res. 2016;7(4):123-129. DOI:10.14740/cr480w 